Inszenierte Kriegsbegeisterung und ohnmächtiger Friedenswille 
JÖRG BOHSE

\section{Inszenierte \\ Kriegsbegeisterung und ohnmächtiger Friedenswille}

Meinungslenkung und Propaganda im Nationalsozialismus

J. B. METZLERSCHE VERLAGSBUCHHANDLUNG STUTTGART 
Bohse, Jörg:

Inszenierte Kriegsbegeisterung und ohnmächtiger Friedenswille:

Meinungslenkung u. Propaganda im Nationalsozialismus/

Jörg Bohse. - Stuttgart: Metzler, 1988

ISBN 978-3-476-00647-9

ISBN 978-3-476-00647-9

ISBN 978-3-476-03265-2 (eBook)

DOI 10.1007/978-3-476-03265-2

Dieses Werk einschließlich aller seiner Teile ist urheberrechtlich geschützt. Jede Verwertung außerhalb der engen Grenzen des Urheberrechtsgesetzes ist ohne Zustimmung des Verlages unzulässig und strafbar. Das gilt insbesondere für Vervielfältigungen, Übersetzungen, Mikroverfilmungen und die Einspeicherung und Verarbeitung in elektronischen Systemen.

(c) 1988 Springer-Verlag GmbH Deutschland

Ursprünglich erschienen bei J. B. Metzlersche Verlagsbuchhandlung und Carl Ernst Poeschel Verlag GmbH in Stuttgart 1988 
Den Kundgebungen des Regimes

Folgen wie Schatten

Die Gerüchte.

Die Regierenden brüllen.

Das Volk flüstert.

Bertolt Brecht 


\section{INHALT}

\section{Einleitung 1}

\section{Formen nationalsozialistischer Meinungskontrolle als Ausdruck ungelöster gesellschaftlicher Konflikte 11}

\section{Begründung der spezifischen Notwendigkeit nationalsozialistischer Meinungs-Kontrolle 11}

Meinungsforschung als conditio sine qua non der Massenkommunikation (11); Gegnerbeobachtung und Erfolgskontrolle: Die "Vertraulichen Berichte " verschiedener Dienststellen (14); "Deutsche Lebensgebietsberichterstattung «: Der Apparat des SD (16); Die politische Funktion der "Meldungen aus dem Reich " (19); Vom Nutzen der NS-Meinungsforschung für die Propagandaanalyse (22)

2. Diskussion der Befunde nationalsozialistischer Meinungs-Kontrolle 26

Themen und Bezugskategorien der informellen Meinungsbildung (26); Einstellungen der Bevölkerung zum Krieg (28); Versorgungslage und "Technik der Entvölkerung " (35); Arbeitsbedingungen: Novembertrauma und Sozialpolitik (41); Personalistische Systemkritik als Grundlage propagandistischer "Parasitenpolemik « (45); Glaubwürdigkeit der Medien und Manipulationsbewußtsein (48); Informelle Modifikationen des offiziellen

Feindbildes (50); Desiderate (54)

\section{Strategien nationalsozialistischer Meinungsformierung als Versuch der Manipulation unaufgelöster Widersprüche 57}

1. Funktionsbestimmung von Propaganda:

Meinungsformierung und Verhaltenseinübung 57

Der Integrationsmodus >Propaganda und der Widerspruch von sozialer 
Funktion und Massenbasis des Faschismus (57); Die Offensive des Großkapitals und eine "neue Ära" der Massenlenkung (58); Wirkungen (60)

\section{Entwürfe zum Strukturwandel der Propaganda 1928-1939 61}

»Strategie der Negation « und Machtübertragung 1933 (61); Repräsentative Scheinöffentlichkeit als Reformersatz (64); Das durchorganisierte Scheinplebiszit der Reichsparteitage (65); Bückeberg: Bauernstand und Staatswürde (65); Feiern zum ersten Mai als gewaltumstellter Konsens (65); Zum Surrogatcharakter appellatorischer Öffentlichkeit (67);

Die Realität des Scheins und seine praktische Bedeutung (68)

3. Soziale Widerspruchsdynamik in der Kriegspropaganda 72

Widerspruchsdynamik 1942/43 (72); Zwischen Verharmlosen, Ablenken und Verschweigen: Propagandataktik in der stagnierenden Phase faschistischer Expansion (74); "Neue Realistik « in der akzelerierenden Krise des NS-Systems (83); "Kraft durch Furcht" als Mobilisierungsmittel (90);

Propaganda des Terrors (95)

\section{Dialektik des pseudoklassenkämpferischen Inhalts der nationalsozialistischen Meinungsformierung als Folge des unaufgelösten Klassenkonflikts - Goebbels' Rede zum »Totalen Krieg« 97}

\section{Inszenatorische Vorbereitung 97}

2. Zum Zusammenhang von »idealistischer Innerlichkeit " und "heroischem Realismus « in der NS-Rhetorik 99

Innerlichkeit (99); Funktionswandel der Innerlichkeit (100); Der Kampf gegen den Bürger als Rettung des Bourgeois (102)

\section{Pseudoklassenkampf als zentrale Kategorie der Faschismusanalyse 106}

»Mit dem Volk durch Dick und Dünn « oder der umfunktionierte Antikapitalismus (106); " Der Angriff - Für die Unterdrückten / Gegen die Ausbeuter « (110); Das Feindbild als Projektion der eigenen sozialen Misere (113);

Die Gleichheit im Übel als Mittel gegen das Übel der Gleichheit (117) 
4. Zur propagandistischen Integrationswirkung des Fübrermythos 121, Ubiquitäres Führerbild (121); Führerfunktionen (123); Teilvernunft im Führerkult (124); Compliance (127); Sozialpsychologie der Goebbelsschen Maieutik (130)

Schlußbemerkung 133

Anmerkungen 137

Literatur 175 